\title{
Long-term Results of Hybrid Total Knee Arthroplasty: Minimum 10-years Follow-up
}

Young Joon Choi, $\mathrm{MD}^{1}$, Ki Won Lee, $\mathrm{MD}^{1}$, Chung Hwan Kim, $\mathrm{MD}^{1}$, Hyung Sun Ahn, $\mathrm{MD}^{1}$, Jae Kwang Hwang, $\mathrm{MD}^{1}$, Jeong Ho Kang, $\mathrm{MD}^{1}$, Hee Don Han, $\mathrm{MD}^{2}$, Wan Jong Cho, $\mathrm{MD}^{1}$ and Jun Seok Park, $\mathrm{MD}^{1}$

Department of Orthopedic Surgery, ${ }^{1}$ Gangneung Asan Hospital, University of Ulsan College of Medicine, Gangneung; ${ }^{2}$ Yonsei University College of Medicine, Seoul, Korea

Purpose: To evaluate the survival rate and long term clinical outcomes of hybrid total knee arthroplasty (TKA).

Materials and Methods: We retrospectively analyzed 113 hybrid TKAs (NexGen) in 86 patients that were followed for more than 10 years. KaplanMeier survival curves were generated using revision as an end point. Knee Society Score (KSS) and range of motion were evaluated for clinical assessment and plane radiographs were used to evaluate implant problems.

Results: At 11.2 years (range, 10 to 12.2 years) of follow-up on average, 7 knees required revision. The reason for revision was aseptic loosening in 4 knees ( 1 in femoral and tibial component and 3 in tibial component only) and infection in 3 knees. The survival rate was $93.8 \%$ at 12 years for all knees, and $96.5 \%$ when septic loosening was excluded. The KSS improved from 29.3 to 91.5 in the Cruciate-Retaining type (CR) and from 21.5 to 90.3 in the posterior stabilizing type (PS) at latest follow-up. The average range of motion was improved from $120.6^{\circ}$ to $133.8^{\circ}$ in the CR type and $119.5^{\circ}$ to $135.5^{\circ}$ in the PS type.

Conclusions: Hybrid TKA provides good survival rates and clinical results comparable to cemented TKA.

Key words: Total knee arthroplasty, Hybrid, Long term follow-up, Survival rate.

\section{Introduction}

Total knee arthroplasty (TKA) has evolved significantly since the 1960s and TKAs using a variety of prosthesis deigns have been documented in many studies ${ }^{1-3)}$. Although TKA has contributed to improvement of patient's quality of life, it has been associated with some complications including osteolysis, component loosening, and polyethylene wear. To prevent these

Received May 2, 2011; Revised (1st) July 24, 2011;

(2nd) September 15, 2011; Accepted October 30, 2011.

Correspondence to: Ki Won Lee, MD.

Department of Orthopedic Surgery, Gangneung Asan Hospital,

University of Ulsan College of Medicine, 38 Bangdong-gil, Gangneung 210-711, Korea.

Tel: +82-33-610-3249, Fax: +82-33-641-8050

Email: osteotome@hanmail.net

This is an Open Access article distributed under the terms of the Creative Commons Attribution Non-Commercial License (http://creativecommons.org/licenses/by-nc/3.0/) which permits unrestricted non-commercial use, distribution, and reproduction in any medium, provided the original work is properly cited. postoperative complications, various fixation techniques have been employed ${ }^{4,5}$. Currently, hybrid fixation has become the most preferred alternative to cementless fixation that has been receiving conflicting reviews. Survivorship of hybrid TKA is high according to many short-term follow-up studies ${ }^{6-8)}$, but it has not been fully investigated in long-term studies ${ }^{9,10}$. The purpose of our study was to evaluate the survivorship and clinical and radiographic results of hybrid TKA during $\geq 10$ years of followup.

\section{Materials and Methods}

\section{Materials}

Of the 168 TKAs performed by the same surgeon at our institution between April 1997 and May 1999, 139 (82.8\%) were hybrid TKAs. Of these, 113 TKAs (86 patients) with a minimum follow-up of 10 years were included in this study. Hybrid TKA was indicated when neither the interfacial gap between the bone and a trial prosthesis after bone resection nor movement of the trial prosthesis during joint motion was observed with the naked eye. The mean follow-up period was 11 years and 2 months (range, 10 years to 12 years and 2 months). There were 5 males and 81 
females with a mean age of 62.9 years (range, 48 to 77 years) (Table 1).

\section{Preoperative Diagnosis}

The preoperative diagnosis was degenerative arthritis in 106 knees (93.8\%), osteonecrosis in 4 knees (3.5\%), rheumatoid arthritis in one knee $(0.9 \%)$, and post-traumatic arthritis in 2 knees (1.8\%).

\section{Implant}

The same hybrid prosthesis (NexGen, Warsaw, IN, USA)

Table 1. Demographic Data

\begin{tabular}{lccc}
\hline & CR type & PS type & Loosened patients \\
\hline Number of knees & 74 & 33 & 6 \\
Mean age & $63( \pm 7.6)$ & $66( \pm 7.5)$ & $56.4( \pm 8.8)$ \\
Gender (male/female) & $8 / 66$ & $6 / 27$ & $1 / 5$ \\
Diagnosis & & & \\
$\quad$ Osteoarthritis & 68 & 32 & 6 \\
Rheumatoid arthritis & 0 & 1 & 0 \\
Osteonecrosis & 4 & 0 & 0 \\
Traumatic arthritis & 2 & 0 & 0 \\
\hline
\end{tabular}

CR: cruciate retaining, PS: posterior substituting. with a cemented tibial component and a cementless femoral component was used in all knees. The patient's age, preoperative deformity and contracture, and intraoperative evaluation of the posterior cruciate ligament (PCL) were taken into consideration for determining either a cruciate-retaining (CR) or a posterior stabilizing (PS) design. The CR design was used in keens with $\geq 10^{\circ}$ of varus deformity or $\geq 15^{\circ}$ of flexion contracture before surgery. The PS design was used when lift off was observed after bone resection for the use of CR design. The CR prosthesis was used in 52 patients ( 70 knees) and the PS prosthesis in 34 patients (43 knees) (Fig. 1).

\section{Survivorship Analysis}

The accumulative survival rate was calculated using the KaplanMeier method. The follow-up period was divided into one year intervals. Annual success was defined as a prosthesis in situ and failure as implant removal due to deep infection or revision. Survival rates, standard deviations and confidence intervals were calculated using SPSS ver. 15.0 (SPSS Inc., Chicago, IL, USA). Analysis of survivorship data was performed using the log-rank test.

\section{Clinical Assessment}

According to the American Knee Society rating system ${ }^{11}$, knee score and function score were assessed preoperatively and at the
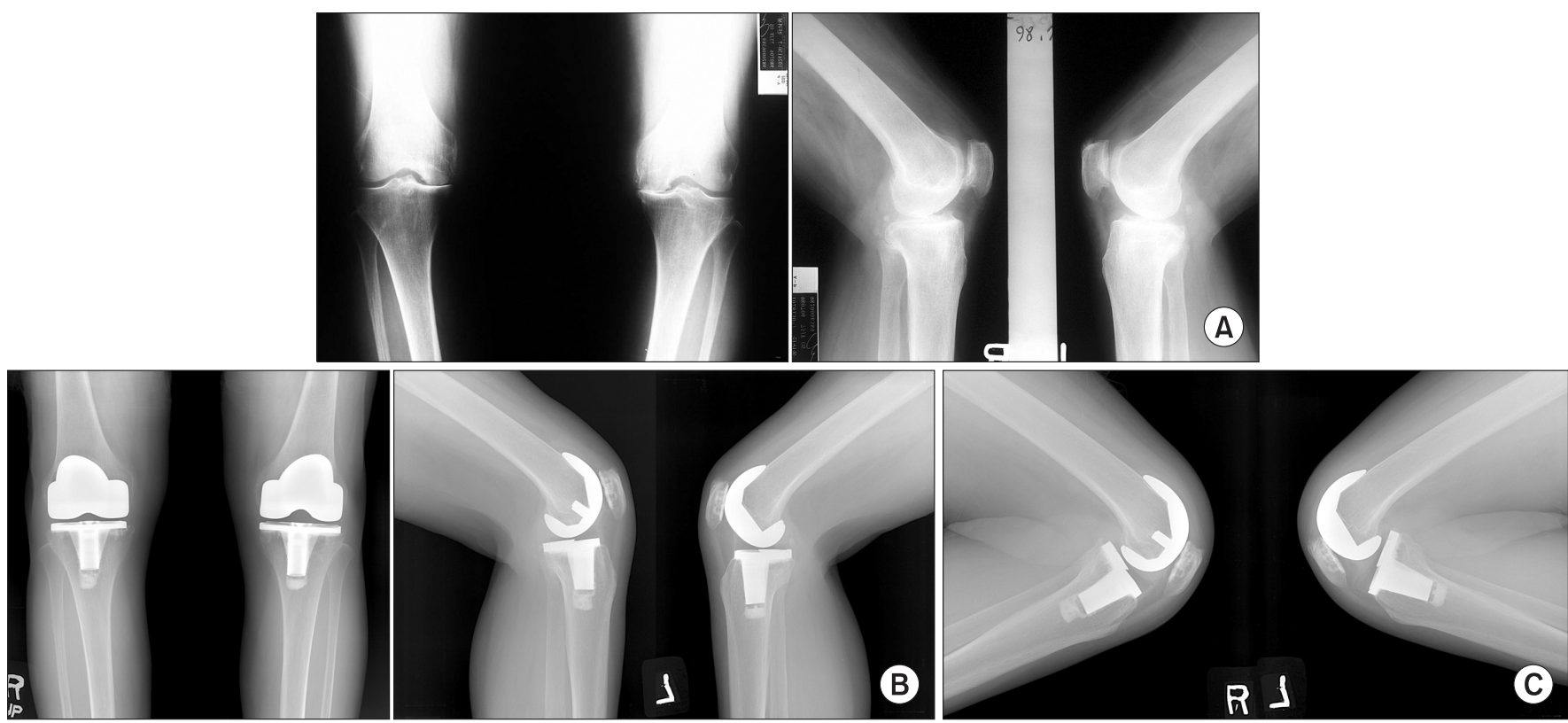

Fig. 1. A 65-year-old female who had undergone total knee arthroplasty on both knees. (A) Preoperative anteroposterior and lateral radiographs show osteoarthritic changes. (B) The cruciate retaining type implant in the right knee and posterior stabilizing type in the left knee were inserted. After 12 years, the radiographs show no loosening on both components. (C) After 12 years, the full-flexion film shows excellent flexion on both knees. 
last follow-up. The 100-point knee score consisted of pain (50 points), range of motion ( 25 points; 1 point for $5^{\circ}$ ), mediolateral stability (15 points), and anteroposterior stability (10 points). Points were deducted for flexion contracture, extension lag, and malalignment. The 100-point function score included walking ability (50 points) and stair climbing (50 points). Points were subtracted for the use of one cane (5 points), 2 canes (10 points), and crutches or walker (20 points).

\section{Radiographic Assessment}

Standing anteroposterior (AP) view, $30^{\circ}$ flexion lateral view, and axial view of both patellae were obtained preoperatively, 2 weeks postoperatively, one year postoperatively, and at final followup. According to the American Knee Society roentgenographic evaluation and scoring system ${ }^{12)}$, the obtuse angle $(\alpha)$ between the axis of the femur and tibial component on the anteroposterior radiograph and the acute angle $(\gamma)$ between the 2 reference points on a lateral radiograph were measured. The appearance of radiolucent lines was examined. Measurements were performed by one orthopedic surgeon and one orthopedic resident; the mean values of the measurements of the 2 observers were recorded for analysis. The interclass correlation coefficients between the 2 observers were $\geq 0.91$ for all data whichindicated sufficiently high interobserver reliability, considering that a value between 0.81 and 1.00 is considered satisfactory ${ }^{13)}$.

\section{Statistical Analysis}

SPSS (SPSS Inc.) was the computer program used for statistical analysis. Paired t-tests were performed to determine statistical significance in the differences between the CR group and PS group. A p-value $<0.05$ was considered statistically significant. Survival rate was calculated by the Kaplan-Meier method. Survival rate was analyzed using the log-rank test.

\section{Results}

\section{Clinical Results}

The mean knee score was improved from 29.3 (range, 0 to 60) preoperatively to 91.5 (range, 60 to 100) postoperatively, in the CR group $(\mathrm{p}<0.001)$, and from 21.5 (range, 0 to 30 ) preoperatively to 90.3 (range, 77 to 100) postoperatively, in the PS group ( $\mathrm{p}<0.001)$. The mean function score was improved from 48.7 (range, 5 to 70 ) preoperatively to 76.1 (range, 35 to 100 ) postoperatively, in the CR group ( $\mathrm{p}<0.001$ ), and from 40.2 (range, 5 to 50 ) preoperatively to 66.2 (range, 40 to 100 ) postoperatively, in the PS group ( $\mathrm{p}=0.002$ ) (Table 2$)$. No statistically significant differences were found between the 2 groups in the knee score or the function score $(\mathrm{p}=0.953)$. On the range of motion ( $\mathrm{ROM})$ assessment, the mean flexion contracture was improved from $5.7^{\circ}$ (range, $0^{\circ}$ to $15^{\circ}$ ) preoperatively to $0^{\circ}$ postoperatively in the CR group ( $\mathrm{p}<0.001$ ), and from $11.5^{\circ}$ (range, $0^{\circ}$ to $20^{\circ}$ ) preoperatively to $0.3^{\circ}$ (range, $0^{\circ}$ to $2^{\circ}$ ) postoperatively, in the PS group ( $\mathrm{p}<0.001$ ). The mean maximum flexion increased from $126.3^{\circ}$ (range, $55^{\circ}$ to $150^{\circ}$ ) preoperatively to $133.8^{\circ}$ (range, $145^{\circ}$ to $150^{\circ}$ ) postoperatively in the CR group $(\mathrm{p}<0.001)$ and from $131.0^{\circ}$ (range, $125^{\circ}$ to $150^{\circ}$ ) preoperatively to $135.8^{\circ}$ (range, $125^{\circ}$ to $150^{\circ}$ ) postoperatively in the PS group ( $\left.\mathrm{p}=0.008\right)$. The mean ROM increased from $120.6^{\circ}$ (range, $15^{\circ}$ to $150^{\circ}$ ) preoperatively to $133.8^{\circ}$ (range, $135^{\circ}$ to $150^{\circ}$ ) postoperatively, in the CR group ( $\mathrm{p}<0.001$ ), and from $119.5^{\circ}$ (range, $100^{\circ}$ to $150^{\circ}$ ) preoperatively to $135.5^{\circ}$ (range, $130^{\circ}$ to $150^{\circ}$ ) postoperatively in the PS group ( $<<0.001$ ) No statistically significant difference was noted between the 2 groups in the ROM assessment ( $\mathrm{p}=0.633$ ).

\section{Radiographic Assessment}

Component loosening occurred in 7 knees: septic loosening in 3 knees and aseptic loosening in 4 knees. In the latter 4 knees, tibial component loosening only was seen in 3 knees (Fig. 2); femoral and tibial component loosening occurred in one knee. One to $2 \mathrm{~mm}$ radiolucent lines appeared around the femoral component in 2 knees (5.7\%) and around the tibial component in 25 knees (23.8\%) in the CR group, but no progression was noted during the follow-up (Table 3).

\section{Survival Rate Analysis}

The survival rate at 12 years after surgery was $93.8 \%$ for all knees and $96.5 \%$ when deep infection was excluded. No statistically significant difference between the groups was found

Table 2. Knee Society Score and Knee Function Score

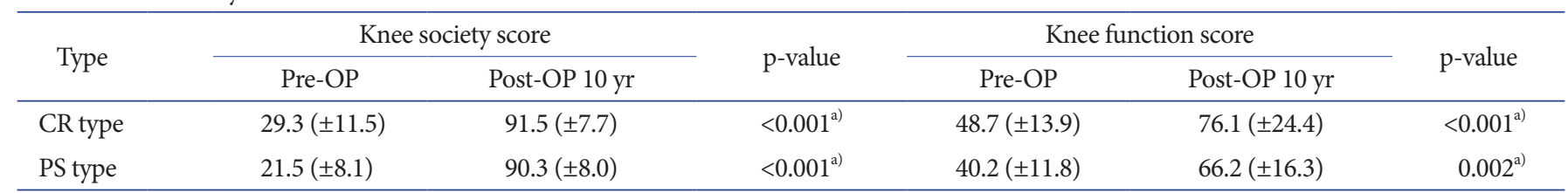

Pre-OP: preoperative, Post-OP: postoperative, CR: cruciate retaining, PS: posterior substituting.

${ }^{a}$ Statistical significance $(\mathrm{p}<0.05)$. 

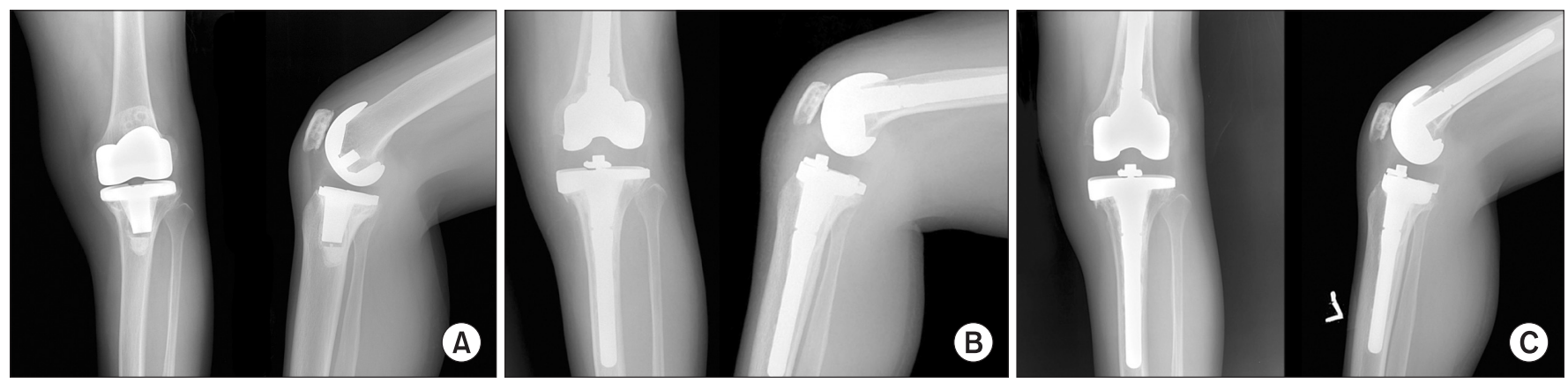

Fig. 2. A 57-year-old female has been performed cruciate retaining -type total knee arthroplasty on the left knee. (A) Six years after the operation, the radiograph shows loosening of the tibial component. (B) Revision arthroplasty was performed. (C) Five years after the revision arthroplasty, the radiograph shows no loosening of the prosthesis.

Table 3. Radiological Evaluation of Femoral Component

\begin{tabular}{|c|c|c|c|c|c|c|}
\hline \multirow{2}{*}{ Type } & \multicolumn{2}{|c|}{$\alpha$ angle } & \multirow{2}{*}{ p-value } & \multicolumn{2}{|c|}{$\gamma$ angle } & \multirow{2}{*}{ p-value } \\
\hline & Imm. post-OP & Post-OP $10 \mathrm{yr}$ & & Imm. post-OP & Post-OP $10 \mathrm{yr}$ & \\
\hline $\mathrm{CR}$ & $97.5( \pm 1.4)$ & $96.6( \pm 2.5)$ & 0.662 & $3.7( \pm 2.4)$ & $2.4( \pm 1.4)$ & 0.128 \\
\hline PS & $98.0( \pm 2.1)$ & $97.0( \pm 2.3)$ & 0.027 & $4.0( \pm 2.3)$ & $2.9( \pm 2.0)$ & 0.149 \\
\hline
\end{tabular}

Imm. post-OP: immediate postoperative, CR: cruciate retaining, PS: posterior substituting, post-OP: postoperative.

${ }^{\text {a) }}$ Statistical significance $(\mathrm{p}<0.05)$.

A

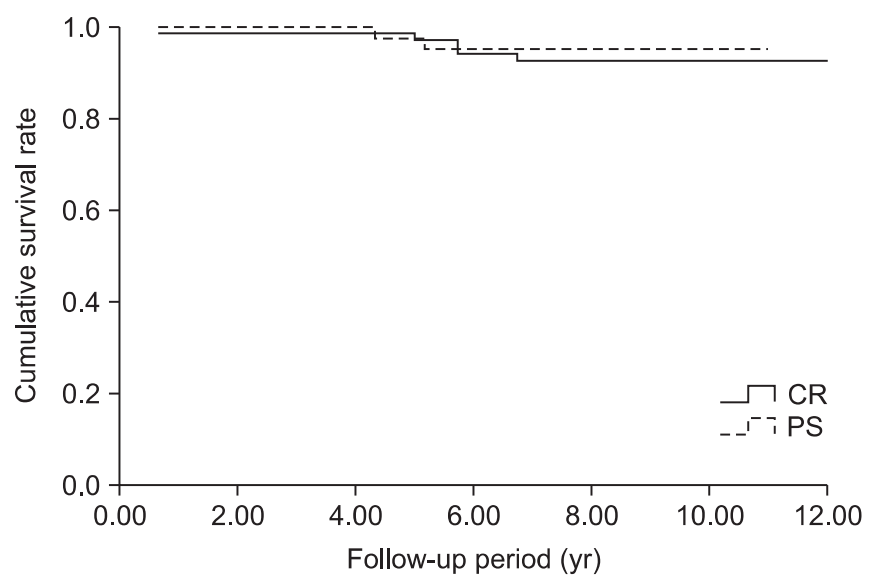

B

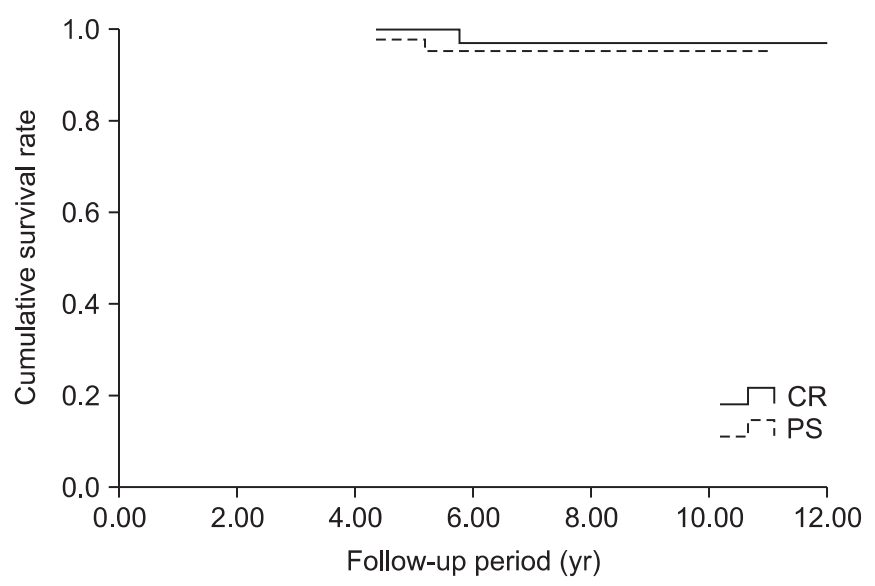

Fig. 3. Kaplan-Meier survival curves were generated: (A) Including Infection. (B) Excluding Infection. CR: cruciate retaining, PS: posterior stabilizing.

on 12-year survival rate ( $\mathrm{p}=0.632)$ (Fig. 3).

\section{Complications}

Revision, defined as failure, was required in 7 knees. Infection was the cause of revision in 3 knees in the CR group and aseptic loosening in the remaining 4 knees, 2 in the PS group and the other 2 in the PS group. There were no periprosthetic fractures or patella dislocations. These complications occurred at a mean of 81 months after surgery and did not recur after revision.

\section{Discussion}

Efforts have been made continuously to elucidate factors that may be associated with the survivorship of TKA. Rand and Ilstrup ${ }^{14)}$ analyzed the success rates of TKA in 9,200 knees: the rates of implant survival were $99 \%$ at 2 years postoperatively, $98 \%$ at 5 years postoperatively, and $91 \%$ at 10 years postoperatively in knees with a CR TKA and the rates were similar in knees with a PS TKA. They suggested that primary arthroplasty, rheumatoid arthritis, 
$\geq 60$ years of age, and use of a metal backed tibial component could be variables for prolonged survival of TKA. In the current study, the survivor rate was $93.8 \%$ at 12 years postoperatively, similar to that in the abovementioned study and there were no remarkable differences between the CR group and the PS group.

Fixation method may be associated with the survivorship of TKA. Hybrid fixation method was first introduced in the late 1980s with a goal of overcoming the most common cause of failure in cementless TKA, tibial component loosening, by promoting bone ingrowth into uncemented components. The technique has been considered advantageous in reducing polyethylene wear that can occur due to third body wear from bone cement debris, decreasing operative time, and allowing for ease of revision ${ }^{6}$. In a study by Campbell et al. ${ }^{15)}$, hybrid TKA resulted in significantly low survival rate compared to cemented TKA during a 5-year follow-up period. However, there have been many studies reporting good short-term follow-up results ${ }^{6,7)}$, and the technique produced no significantly different results compared to cemented TKA in a 12.8-year long-term followup study ${ }^{16)}$. The survival rate was 95\% after hybrid TKA in some studies involving a 15 -year follow-up period ${ }^{17-20)}$. Such high long-term survivorship of hybrid TKA has been attributed to improvement in implant design and surgical technique ${ }^{9)}$, the use of porous-coated femoral component and non-porous-coated tibial component ${ }^{21)}$, and proper fitting between the implant and the femur ${ }^{21)}$. We believe these factors contributed to the excellent long-term survival rate in our study. The femoral component was porous-coated in all knees. Uncemented fixation was performed only when bone-implant interfacial gap was not observed in the naked eye after femoral bone resection. Cemented fixation was used when incongruity between the cut surface and the implant was noted or stable fixation appeared unachievable during trial insertion and $\geq 1 \mathrm{~mm}$ interfacial gap was observed. Uncemented fixation can result in osteolysis due to polyethylene wear particle interposition between the implant and the bone. However, the incidence of osteolysis around the femoral component is significantly low ${ }^{9)}$ and uncemented fixation yields fewer radiolucent lines than cemented fixation in zone 4 where ingress of debris particles between the component and the femur occurs $^{22)}$. Osteolysis is more frequently observed around the tibial component. In this study, femoral component loosening occurred only in one knee of the four knees with component loosening and radiolucent lines in zone 4 were observed in one case. Therefore, we thought the incidence of osteolysis around the femoral component could be reduced by choosing proper implants and fixation methods. In addition, considering that femoral component loosening and tibial component loosening both occurred in this one case, we could not rule the possibility of spontaneous resolution of infection in the past.

There has been debate whether the PCL should be retained or removed during TKA and retention, resection, and conditional retention of the PCL have been suggested as possible options ${ }^{23,24)}$. PCL retention allows for efficient walking, increased ROM, higher resistance to posterior shear force for stability, and preservation of the joint surface height and sensory function ${ }^{25-27)}$. On the other hand, PCL resurfacing facilitates deformity correction, small tibial bone resection, and joint conformity for polyethylene wear reduction ${ }^{24)}$. In this study, no statistically significant differences were noted between the CR group and PS group in terms of the postoperative knee score, function score, and survival rate.

This study is limited in that only one system was used in all the TKAs and the results were reviewed, retrospectively. However, the significance of this study is that it shows that the long-term survival rate of hybrid TKA using the NexGen implant was comparable to cemented TKA ( $98.3 \%$ in the $\geq 5$-year follow-up study by Bin et al. ${ }^{28)}$ and $87.6 \%$ in the 10 -year follow-up study by Duffy et al. $^{29)}$ ). In addition, hybrid TKA resulted in excellent postoperative ROM.

\section{Conclusions}

Hybrid TKA using the NexGen implant yielded results comparable to cemented TKA in terms of clinical results, including ROM and function, and radiographic results in a minimum 10-year follow-up.

\section{References}

1. Buehler KO, Venn-Watson E, D'Lima DD, Colwell CW Jr. The press-fit condylar total knee system: 8- to 10-year results with a posterior cruciate-retaining design. J Arthroplasty. 2000;15:698-701.

2. Laskin RS. The Genesis total knee prosthesis: a 10-year followup study. Clin Orthop Relat Res. 2001;(388):95-102.

3. Stern SH, Insall JN. Posterior stabilized prosthesis. Results after follow-up of nine to twelve years. J Bone Joint Surg Am. 1992;74:980-6.

4. Bauer GC. What price progress? Failed innovations of the knee prosthesis. Acta Orthop Scand. 1992;63:245-6.

5. Goodfellow J. Knee prostheses: one step forward, two steps back. J Bone Joint Surg Br. 1992;74:1-2. 
6. Kraay MJ, Meyers SA, Goldberg VM, Figgie HE 3rd, Conroy PA. "Hybrid" total knee arthroplasty with the Miller-Galante prosthesis. A prospective clinical and roentgenographic evaluation. Clin Orthop Relat Res. 1991;(273):32-41.

7. Wright RJ, Lima J, Scott RD, Thornhill TS. Two- to fouryear results of posterior cruciate-sparing condylar total knee arthroplasty with an uncemented femoral component. Clin Orthop Relat Res. 1990;(260):80-6.

8. Rorabeck CH, Bourne RB, Lewis PL, Nott L. The MillerGalante knee prosthesis for the treatment of osteoarthrosis. A comparison of the results of partial fixation with cement and fixation without any cement. J Bone Joint Surg Am. 1993;75:402-8.

9. Faris PM, Keating EM, Farris A, Meding JB, Ritter MA. Hybrid total knee arthroplasty: 13-year survivorship of AGC total knee systems with average 7 years followup. Clin Orthop Relat Res. 2008;466:1204-9.

10. Kim $\mathrm{YH}, \mathrm{Oh} \mathrm{JH}, \mathrm{Oh} \mathrm{SH}$. Osteolysis around cementless porous-coated anatomic knee prostheses. J Bone Joint Surg Br. 1995;77:236-41.

11. Insall JN, Dorr LD, Scott RD, Scott WN. Rationale of the Knee Society clinical rating system. Clin Orthop Relat Res. 1989;(248):13-4.

12. Ewald FC. The Knee Society total knee arthroplasty roentgenographic evaluation and scoring system. Clin Orthop Relat Res. 1989;(248):9-12.

13. Landis JR, Koch GG. The measurement of observer agreement for categorical data. Biometrics. 1977;33:159-74.

14. Rand JA, Ilstrup DM. Survivorship analysis of total knee arthroplasty. Cumulative rates of survival of 9200 total knee arthroplasties. J Bone Joint Surg Am. 1991;73:397-409.

15. Campbell MD, Duffy GP, Trousdale RT. Femoral component failure in hybrid total knee arthroplasty. Clin Orthop Relat Res. 1998;(356):58-65.

16. Parker DA, Rorabeck CH, Bourne RB. Long-term followup of cementless versus hybrid fixation for total knee arthroplasty. Clin Orthop Relat Res. 2001;(388):68-76.

17. Ranawat CS, Flynn WF Jr, Saddler S, Hansraj KK, Maynard MJ. Long-term results of the total condylar knee arthroplasty. A 15-year survivorship study. Clin Orthop Relat Res. 1993;(286):94-102.

18. Rinonapoli E, Mancini GB, Azzara A, Aglietti P. Long-term results and survivorship analysis of 89 total condylar knee prostheses. J Arthroplasty. 1992;7:241-6.

19. Ritter MA, Herbst SA, Keating EM, Faris PM, Meding JB. Long-term survival analysis of a posterior cruciate-retaining total condylar total knee arthroplasty. Clin Orthop Relat Res. 1994;(309):136-45.

20. Scuderi GR, Insall JN, Windsor RE, Moran MC. Survivorship of cemented knee replacements. J Bone Joint Surg Br. 1989;71:798-803.

21. Illgen R, Tueting J, Enright T, Schreibman K, McBeath A, Heiner J. Hybrid total knee arthroplasty: a retrospective analysis of clinical and radiographic outcomes at average 10 years follow-up. J Arthroplasty. 2004;19:95-100.

22. Huddleston JI, Wiley JW, Scott RD. Zone 4 femoral radiolucent lines in hybrid versus cemented total knee arthroplasties: are they clinically significant? Clin Orthop Relat Res. 2005;441:334-9.

23. Andriacchi TP, Galante JO. Retention of the posterior cruciate in total knee arthroplasty. J Arthroplasty. 1988;3 Suppl:S13-9.

24. Freeman MA, Railton GT. Should the posterior cruciate ligament be retained or resected in condylar nonmeniscal knee arthroplasty? The case for resection. J Arthroplasty. 1988;3 Suppl:S3-12.

25. Andriacchi TP, Galante JO, Fermier RW. The influence of total knee-replacement design on walking and stairclimbing. J Bone Joint Surg Am. 1982;64:1328-35.

26. Dorr LD, Ochsner JL, Gronley J, Perry J. Functional comparison of posterior cruciate-retained versus cruciatesacrificed total knee arthroplasty. Clin Orthop Relat Res. 1988;(236):36-43.

27. Kelman GJ, Biden EN, Wyatt MP, Ritter MA, Colwell CW Jr. Gait laboratory analysis of a posterior cruciate-sparing total knee arthroplasty in stair ascent and descent. Clin Orthop Relat Res. 1989;(248):21-5.

28. Bin SI, Nam TS, An JH, Jung KH, Kim JM, Yoon YS. Result of total knee arthroplasty using nexgen system. J Korean Orthop Assoc. 2007;42:59-63.

29. Duffy GP, Berry DJ, Rand JA. Cement versus cementless fixation in total knee arthroplasty. Clin Orthop Relat Res. 1998;(356):66-72. 